\title{
Changes of Some Engineering Properties of Coffee Beans Due to Roasting Process
}

\author{
Dadang D Hidayat ${ }^{1 *}$, Ashri Indriati ${ }^{2 *}$, Cecep E Andriansyah ${ }^{3 *}$, \\ Ari Rahayuningtyas ${ }^{4 *}$, Arie Sudaryanto ${ }^{5 *}$ \\ ${ }^{1,2,3}$ Research Center for Appropriate Technology, Indonesian Institute of Sciences \\ Jl. KS. Tubun No.5 Subang, West Java, Indonesia \\ *Corresponding author's email: ${ }^{1}$ zehidayat [AT] gmail.com \\ ${ }^{2}$ ashriindriati [AT] gmail.com
}

\begin{abstract}
The changes in physical, mechanical, and colours after roasting in two-level were investigated. Aims of this study were to evaluate changes in the physical, mechanical, and colours due to the roasting process of the Arabica and Robusta coffee bean grown in Cisalak Sub-District, Subang District-West Java. Results of analysis determined that the roasting process resulted in decreasing the moisture content of green coffee bean from $13.8 \%$ to $6,54 \%$ of first-level roasted bean and 6.24 of the second-level roasted bean, while that of robusta decreased from $11.22 \%$ to 7.56 and $6.12 \%$. First-level roasting was categorised as a light roast, while the second-level was a medium roast. The Roast Weight Loss of arabica and robusta from green to light roast bean were $19.45 \%$ and $16,24 \%$, respectively, and that to medium roast bean was $26.20 \%$ and $22.37 \%$, respectively. The roast volume change of arabica and robusta from green to light roast bean were $50.55 \%$ and $44.30 \%$ respectively, and that to medium roast bean were $54.65 \%$ and $55.92 \%$ respectively. The total colour differences between green with light and medium roast bean of arabica were 6.39 and 2.52 , while that of robusta were 6.19 and 2.49 , respectively.
\end{abstract}

Keywords-Coffee Beans, Roasting Process, Engineering Properties, Coffee Beans Process

\section{INTRODUCTION}

In general, there are two types of coffee processing stages, i.e. primary and secondary. The primary processing consisted of wet and dry methods. The different of these two systems principally is in the bean separation stage. The basic operations of the dry method are harvesting, drying and hulling, and that of the wet is harvesting, pulping, fermentation and washing, drying peeling and polishing. The end product of primary processing is green coffee. The green coffee is dry beans after hulling. The secondary processing is further processing before consumption which includes cleaning, blending, roasting and grinding [1][2].

Roasting is an essential pre-processing treatment for some seeds such as wattle seed [3], Almond nut [4], and cocoa beans [5]. For coffee, roasting is probably the essential step in coffee processing, causing marked chemical, physical, structural and sensorial changes [6][7][8]. The green coffee beans provide neither aroma nor flavour. The green coffee bean will exude the irresistible coffee flavours and aromas only when roasted on intense heat. Aromatic and taste qualities of the coffee are developed during roasting. A significant objective in roasting is the achievement of uniformity; this will be obtained by the constant movement of the bean in the roaster and by good grading and sorting beforehand. Coffee roasters operate by the passage of hot air through the rotating drum, fixed drum, fluid bed or spouted bed [9][10][11][12].

During roasting, not only a series of complex chemical but also physical processes take place to transform green coffee into the roasted beans, and some changes occur. The changes that arise among them are water loss, weight decreasing, volume increasing, density lowering, colour changing and oil migrating toward the coffee bean surface [11][13][14][15]. The roasting conditions may also give an impact on significant changes in the textural properties of the coffee bean; during this process, beans lose their strength and toughness and become more frangible and brittle [16]. Intense heat during roasting process imparts the external cellulose structure and makes the outer shell porous [17], and alters the porosity [12]. There are many studies conducted on the engineering property of the coffee bean. This sort of study is particularly essential to the mechanisation in designing and manufacturing the associated equipment. To design and manufacture of equipment, to process of agricultural materials, and to convert these materials into food, demands an 
understanding of their physical properties [18]. Although there are many studies conducted on the engineering property of coffee bean, however, its features differ relying on many factors such as the geographical area of plantations, soil type, sun exposure, methods of harvesting, processing methods and storage conditions, roaster skills, and packaging of roasted coffee [1][2]. Therefore, this study aimed to evaluate changes in the physical, mechanical, and colours due to the roasting process of the Arabica and Robusta coffee bean grown in Cisalak Sub-District, Subang District-West Java.

\section{MATERIALS AND METHODS}

\subsection{Material Preparation}

Coffee samples consisted of full wash Arabica and Robusta green bean. The samples were collected from coffee farmers located in Cupunagara village (Latitude 6046'57.71"S, Longitude 107²41'37.15"E, and elevation 1153 MAMSL), Cisalak sub-district, Subang district, West Java province. The coffee bean sample was roasted using a drum roaster. The measurement of coffee bean properties included physical, mechanical and colour. The physical properties consisted of moisture content, size and shape, mass, volume, particle density, bulk density, and porosity. Their mechanical properties consisted of hardness, fracturability, emptying angle of repose, filling angle of repose and friction. The colour properties consisted of lightness $\left(\mathrm{L}^{*}\right)$, red-green coordinates $\left(\mathrm{a}^{*}\right)$, yellow-blue coordinates $\left(\mathrm{b}^{*}\right)$, chroma $\left(\mathrm{C}^{*}\right)$ and hue angle $\left(\mathrm{h}^{*}\right)$.

\subsection{Roasting procedure}

The roaster used to roast the Arabica, and Robusta coffee bean sample was drum type which had capacity 750 -gram. The drum and cooling bin equipped with an agitator, which was a component of a roaster were driven by a 25 -watt electromotor respectively. The green bean (GB) samples were treated on two roasting degrees. In the first degree(RB1), they were roasted until a few minutes after the first crack and in the second level (RB2) a few minutes after the second crack. The preheating temperature was $180^{\circ} \mathrm{C}$; the roaster drum rotated in $67.5 \mathrm{rpm}$, and the airflow rate was $2.5 \mathrm{~m}^{3} / \mathrm{min}$. After roasting the sample was cooled in the bin for about 4 minutes until the roasted bean temperature reached $\leq 400^{\circ} \mathrm{C}$. The agitator of cooling bin rotated in $35 \mathrm{rpm}$.

\subsection{Moisture content}

The moisture content of green and roasted coffee bean was determined by using Wile instrument, with $\pm 0.5 \%$ accuracy, and moisture range from $1 \%$ to $38 \%$. The moisture content measurement was carried out five replication.

\subsection{Size and Dimension}

The amount of the Arabica and Robusta samples consisted of green, and roasted coffee bean was 30, respectively. The primary dimension included length (l), Width (w), and thickness (t) were measured using a digital vernier calliper with an accuracy of $0.01 \mathrm{~mm}$. The secondary dimension included the mean diameter of arithmetic $\left(\mathrm{D}_{\mathrm{am}}\right)$, geometric $\left(\mathrm{D}_{\mathrm{g}}\right)$, surface area $\left(\mathrm{A}_{\mathrm{s}}\right)$, frontal surface area $\left(\mathrm{A}_{\mathrm{fs}}\right)$, cross-sectional area $\left(\mathrm{A}_{\mathrm{cs}}\right)$, a coefficient of contact surface $\left(\mathrm{C}_{\mathrm{cs}}\right)$, and sphericity $(\varnothing)$ were calculated from equations (1), (2), (3) and (4),(5), (6), and (7). respectively [19].

$$
\begin{aligned}
& D_{g m}=\sqrt[g]{1 w t} \\
& D_{a m}=\frac{1+w+t}{3} \\
& A_{g}=\pi(\sqrt[8]{1 w t})^{2} \\
& A_{f s}=\frac{\pi}{4} 1 w \\
& A_{t}=\frac{\pi}{4} t w \\
& C_{c s}=\frac{A_{f}-A_{t}}{A_{f}} \\
& \emptyset=\frac{\sqrt[g]{1 w t}}{1}
\end{aligned}
$$

\subsection{Mass}

The mass of an individual sample of a green and roasted coffee bean of Arabica and Robusta were weighed using a digital balance with an accuracy of $0.0001 \mathrm{~g}$. The Roast Weight Loss (RWL) was determined from equation (8)[9][16][20]. Where $\mathrm{W}$ was the weight of coffee bean per roasting batch. 


$$
\mathrm{RWL}=\frac{\mathrm{W}_{\mathrm{GB}}-\mathrm{W}_{\mathrm{RB}}}{\mathrm{W}_{\mathrm{GB}}} \times 100 \%
$$

\subsection{Volume}

The green and roasted bean shape of Arabica and Robusta were assumed as half a triaxial ellipsoid and calculated using Equation (9)[15]. The Roast Volume Change (RVC) was calculated using equation (10)[20]. Where v was the individual volume of coffee bean, while $\mathrm{V}$ was the volume of coffee bean per roasting batch.

$$
\begin{aligned}
& \mathrm{v}=\frac{\pi}{6} \mathrm{lwt} \\
& \mathrm{RVC}=\frac{\mathrm{V}_{\mathrm{RB}}-\mathrm{V}_{\mathrm{GB}}}{\mathrm{V}_{\mathrm{RR}}} \times 100 \%
\end{aligned}
$$

\subsection{Density and Porosity}

The volume of samples obtained from equation [9] was used to calculate the particle density. The bulk density of the samples was determined by calculating the weight of $500 \mathrm{ml}$ samples. The test was carried out in four replications [21]. The equation (11), (12), and (13) showed the determination of density, bulk density and porosity.

$$
\begin{aligned}
& \rho_{\mathrm{p}}=\frac{\mathrm{M}}{\mathrm{v}} \\
& \rho_{\mathrm{b}}=\frac{\mathrm{M}_{\mathrm{V} 500}}{\mathrm{~V}_{500}} \\
& \varepsilon=\frac{\left(\rho_{p}-\rho_{b}\right)}{\rho_{p}} \times 100 \%
\end{aligned}
$$

\subsection{Hardness and fracturability}

The hardness and fracturability of the sample were measured using the TA- XT plus Texture Analyser Stable Micro System. The test was carried out in five replications.

\subsection{The Angle of repose and friction}

The angle of repose was measured using a tilt driven by an electromotor and supported by a sensor. Static friction ( $\mu$ ) is calculated using equation (14) [22] [23] [24]. Emptying angles of stationary coefficient and static friction are carried out on two surfaces, namely, stainless steel, and aluminium.

$$
\mu=\tan \theta_{e}
$$

\subsection{Colours}

The colour of samples was measured using a colourimeter $\mathrm{NH} 310$. The analysis methods used were CIE (Commission Internationale de L'Eclairage) $\mathrm{L}^{*} \mathrm{a}^{*} \mathrm{~b}^{*}$ and CIE $\mathrm{L}^{*} \mathrm{c}^{*} \mathrm{~h}^{*}$ coordinates. The test was carried out five replications. The value of $\mathrm{L}^{*}, \mathrm{a}^{*} \mathrm{~b}^{*}$ and $\mathrm{L}^{*} \mathrm{c}^{*} \mathrm{~h}^{*}$ obtained was used to determine the total colour difference between each group of samples. The total colour difference was determined using the f equation (15)[25].

$$
\Delta \mathrm{E}^{*}{ }_{\mathrm{A}-\mathrm{B}}=\sqrt{\left(\Delta \mathrm{L}^{*}\right)^{2}+\left(\Delta \mathrm{a}^{8}\right)^{2}+\left(\Delta \mathrm{b}^{*}\right)^{2}}
$$

\subsection{Statistical analysis}

The data obtained from the measurement and computation were analysed statistically to find out the range of physical, mechanical, and colour properties of Arabica and Robusta green and roasted bean. Paired t-test analysis was applied to evaluate the significance changes from green bean to two levels of the roasted bean due to the roasting process. A significant level of probability $\mathrm{p} \leq 0.05$ was applied for this analysis. 


\section{RESULTS AND DISCUSSION}

\subsection{Moisture content}

Table 1 showed the moisture content of green and roasted coffee bean from different species of coffee. The moisture content of the green Arabica and Robusta coffee bean used in this study was $13.08 \%$ and $11.22 \%$, respectively. The decrease of moisture content from GB to RB1, GB to RB2 and RB1 to RB2 of Arabica coffee bean were 50.00\%, $52.29 \%$ and $4.59 \%$, respectively; while that of Robusta were $32.62 \%, 45.45 \%$ and $19.05 \%$, respectively. Results of paired t-test analysis showed that the changing occurred in both Arabica and Robusta coffee bean due to the roasting process were significant differences, $(\mathrm{t}(4)), \mathrm{p}<0.05$.

Table 1. The moisture content of green and roasted coffee bean

\begin{tabular}{|c|c|c|c|}
\hline \multirow{2}{*}{ Coffee Bean Species } & \multicolumn{3}{|c|}{ Moisture Content, \% } \\
\cline { 2 - 4 } & GB & RB1 & RB2 \\
\hline Arabica & 13,08 & 6,54 & 6,24 \\
Robusta & 11,22 & 7,56 & 6,12 \\
\hline
\end{tabular}

Roasting is generally done by exposing the green beans to either hot gas or laying them on a hot metal surface. The roasting process can be divided into three steps: drying, roasting and cooling. The slow release of water and other volatile substances takes place during the drying step. It is followed by roasting reactions, which results in significant changes to the bean's chemical and physical properties [26, 27]. During the first stage of processing the release of water vapour from the green coffee can reach up to 70\% of initial moisture content [7]. Referred to the processing of roasting, the decrease of moisture content was caused by the hot air flow distribution in the roaster.

\subsection{Size and Dimension}

Table 2 showed the average size and dimension of green coffee bean, first-level roasted bean(RB1), and the secondlevel roasted bean (RB2) of Arabica and Robusta.

Table 2. The average size and dimension of arabica and robusta coffee bean

\begin{tabular}{|c|c|c|c|c|c|c|}
\hline \multirow{2}{*}{ Properties } & \multicolumn{3}{|c|}{ Arabica } & \multicolumn{3}{c|}{ Robusta } \\
\cline { 2 - 7 } & GB & RB1 & RB2 & GB & RB1 & RB2 \\
\hline L (mm) & 10,10 & 12,46 & 12,85 & 8,53 & 9,73 & 10,24 \\
W (mm) & 7,51 & 8,73 & 8,78 & 6,8 & 7,84 & 8,57 \\
t (mm) & 4,27 & 5,08 & 5,21 & 3,79 & 4,9 & 5,22 \\
Dgm (mm) & 6,85 & 8,19 & 8,37 & 6,03 & 7,18 & 7,70 \\
Da (mm) & 7,29 & 8,75 & 8,95 & 6,37 & 7,49 & 8,01 \\
As (mm $)$ & 147,97 & 211,16 & 220,40 & 114,44 & 162,91 & 186,65 \\
Af (mm $\left.{ }^{2}\right)$ & 59,58 & 85,38 & 88,63 & 45,63 & 60 & 69,08 \\
At (mm $\left.{ }^{2}\right)$ & 25,22 & 34,81 & 35,97 & 20,26 & 30,18 & 35,17 \\
Ccs & 0,576 & 0,591 & 0,594 & 0,55 & 0,49 & 0,49 \\
$\varnothing$ & 0,68 & 0,66 & 0,65 & 0,71 & 0,74 & 0,75 \\
\hline
\end{tabular}

Results of the analysis on coffee bean properties determined that the expansion of length from GB to RB1, GB to $\mathrm{RB} 2$, and RB1 to RB2 were $18.98 \%, 21.45 \%$, and $3.05 \%$. Based on paired t-test analysis, the change in length from GB to RB1, GB to RB 2, and RB1 to RB2 at the condition of ( $\mathrm{t}(29), \mathrm{p}=0.00),(\mathrm{t}(29), \mathrm{p}=0.00)$, and $(\mathrm{t}(29), \mathrm{p}=0.048)$, respectively were significantly different.

The change in width from GB to RB1 and to RB2, were $13,94 \%, 14,43 \%$, and $0.57 \%$, respectively. Based on paired $\mathrm{t}$-test analysis, the width change from GB to RB1 and RB2 was a significant difference, $\mathrm{t}(29), \mathrm{p}=0.00$; otherwise, there was no significant difference in the width change from RB1 to RB 2, $t(29), p=0.671$. The same pattern of width change also occurred in coffee bean thickness. There were significant differences in thickness change from GB to RB1 and RB2, $\mathrm{t}(29), \mathrm{p}=0.00$; otherwise, there was no significant difference in thickness change from $\mathrm{RB} 1$ to $\mathrm{RB} 2, \mathrm{t}(29), \mathrm{p}=0.07$. The change of thickness, from GB to RB1 and RB2, and from RB1 To RB2 were $15.93 \%, 18.06 \%$, and $2.53 \%$, respectively.

On the subject of geometric diameter, the change of $16.3 \%$ from GB to RB1 and of 18.08 from GB to RB2, based on paired t-test the analysis determined that their change were differently significant, $t(29), \mathrm{p}=0.00$; otherwise the difference 
of $2.12 \%$ from RB1 to RB2 was not substantial, $t(29), p=0.21$. In respect of arithmetic diameter the change of $16.72 \%$ from GB to RB1, $18.50 \%$ from GB to RB2, at the condition of $\mathrm{t}(29), \mathrm{p}=0.00$, and $2.15 \%$ from RB1 to RB2, at the condition of $\mathrm{t}(29), \mathrm{p}=0.049$, based on paired $\mathrm{t}$-test analysis was significantly different.

In the matter of surface area, the change of $29.93 \%$ from GB to RB1 and $32.86 \%$ from GB to RB2, result of paired $t$ test analysis proved that there were significant differences, $t(29), p=0.00$; otherwise the change of $4,19 \%$ from RB1 to $\mathrm{RB} 2$ was not differently significant $\mathrm{t}(29), \mathrm{p}=0.07$. Relating to the frontal surface area, the change of $30.22 \%$ from GB to $\mathrm{RB} 1,32.77 \%$ from GB to RB2, and 3.67 from RB1 to RB2, based on paired t-test analysis were significant differences, $\mathrm{t}(29), \mathrm{p}=0.00$. The results suggested that it was advisable to store the beans at $13.0 \%$ (wb) moisture content when the surface area is lowest. Therefore beans would present less surface area for moisture absorption during storage.

Regarding the transverse area, the changes that occurred from GB to RB1, and GB to RB2 were significant differences, $t(29), p-=0.00$; otherwise, the change from $R B 1$ to $R B 2$ was no significant difference, $t(29), p=0.26$. Relating to coefficient of contact surface, at the condition of $\mathrm{t}(29), \mathrm{p}=0.24$ the change of $2.59 \%$ occurred from GB to RB $1, t(29), p=0.09$ the change of $2.98 \%$ from GB to RB2, and $t(29), p=0.81$, the change of $0.40 \%$ from RB1 to RB 2 were significant differences. The change in sphericity of $3.38 \%$ from GB to $\mathrm{RB} 1$, at $\mathrm{t}(29), \mathrm{p}=0.049$, and $4.16 \%$ from GB to $\mathrm{RB} 2$ at $\mathrm{t}(29), \mathrm{p}=0.00$ were significant difference; otherwise the change of $0.81 \%$ from RB1 to RB2 at $\mathrm{t}(29), \mathrm{p}=0.54$ was not significant difference.

Almost all of the Robusta coffee bean changes from GB to RB1, GB to RB2, and RB1 to RB2 indicated significant differences, $\mathrm{t}(29), \mathrm{p}<0.05$, except for the changes in coefficient of the contact surface and sphericity from RB1 to RB2, $\mathrm{t}(29), \mathrm{p}>0.05$.

In general, the significant difference of physical properties between coffee bean of Arabica and Robusta was in the change in size. Expansion of Arabica coffee bean tended to elongate rather than the widened or thickened, and that of Robusta tended to widen rather than elongated and thickened. This results indicated that sieving or separating machine with circular holes would be more effectively work applied to Robusta rather than Arabica coffee bean.

The knowledge of the size of seeds such as coffee bean is essential for uniformity and packing in standard cartons [28]. Shape and physical dimensions are essential in screening solids to separate foreign materials and in sorting out various sizes of fruits and vegetables [29].

\subsection{Mass}

Table 3 showed the individual and bulk weight of green and roasted Arabica and Robusta coffee bean. Results of paired t-test analysis showed that there was a significant decrease of Arabica coffee bean mass from GB to RB1 and $\mathrm{RB} 2, \mathrm{t}(29), \mathrm{p}=0.00$; otherwise, there was no significant change of that from RB1 to $\mathrm{RB} 2, \mathrm{t}(29), \mathrm{p}=0.47$. The change of mass from GB to RB1 and RB2 and was $20.06 \%$ and $22.23 \%$, respectively. The change of mass from RB1 to RB2 was $2.71 \%$. Obtaining from the equation (8) the Roast weight Loss, from GB to RB 1, GB to RB2 and RB1 to RB2 were $19.45 \%, 26.20 \%$, and $8.37 \%$. Result of paired t-test analysis the Roasting Weight Loss from GB to RB1, GB to RB2, and $\mathrm{RB} 1$ to RB 2 were significant differences, $\mathrm{t}(3), \mathrm{p}=0.00$.

Table 3.The individual and bulk weight of green and roasted arabica and robusta coffee bean

\begin{tabular}{|c|c|c|c|c|c|c|}
\hline \multirow{2}{*}{$\begin{array}{c}\text { Weight } \\
\text { (W) }\end{array}$} & \multicolumn{3}{|c|}{ Arabica } & \multicolumn{3}{c|}{ Robusta } \\
\cline { 2 - 7 } & GB & RB1 & RB2 & GB & RB1 & RB2 \\
\hline Individual & 0,22 & 0,17 & 0,17 & 0,16 & 0,14 & 0,13 \\
Bulk & 750.00 & 604,12 & 553,52 & 750.00 & 628,19 & 582,22 \\
\hline
\end{tabular}

The changing mass of Robusta coffee bean showed a similar pattern than that of Arabica coffee bean; otherwise, the change percentage of Robusta coffee bean mass was relatively lower than that of Arabica coffee bean. The change of coffee bean mass from GB to RB1, GB to RB2 and RB1 to RB2 was $12.50 \%, 15.88 \%$ and $3.86 \%$. Results of paired ttest analysis determined that the mass change of Robusta coffee bean from GB to RB1 and GB to RB2 were significant differences $t(29), p<0.05$; otherwise the changing of that from RB1 to RB2 was not different significantly, $t(29), p=0.26$. The Roast Weight Loss of robusta coffee bean from GB to RB1, GB to RB2 and RB1 to RB2 were $16.24 \%, 22.37 \%$ and $2.71 \%$, respectively. Result of paired t-test analysis showed that the

Roasting Weight Loss of Robusta coffee bean from GB to RB1, GB to RB2, and RB1 to RB 2 were significant differences, $t(3), p=0.00$. Decrease of mass after roasting was caused by the loss of moisture and transformation of some dry matters into gases. Results of the analysis showed that the higher the moisture content, the higher the bean mass; therefore, transportation is advisable at low moisture content. 


\subsection{Volume}

Due to roasting the individual volume of Arabica coffee bean, increased from GB to RB1, GB to RB2 and RB1 to RB2, with the volume change percentage of $41.32 \%, 44.93 \%$, and $6.15 \%$, respectively, while that of Robusta coffee bean was $40 \%, 50 \%$ and $16.67 \%$. The roast volume change of individual coffee bean from GB to RB1 and GB to RB2 for both Arabica and Robusta were significant differences, $t(29), p=0.00$. The roast volume change of individual coffee bean of Robusta from RB1 to RB2 was also a significant difference; otherwise, that of Arabica was no significant difference, $\mathrm{t}(29), \mathrm{p}=0.07$. Concerning the pattern of roast volume change, the individual coffee bean of Arabica showed similarly than that of Robusta.

Table 4. The individual and bulk volume of green and roasted arabica and robusta coffee bean

\begin{tabular}{|l|c|c|c|c|}
\hline \multicolumn{2}{|c|}{ Properties } & GB & RB1 & RB2 \\
\hline \multirow{2}{*}{ Arabica } & v-individual & 0,17 & 0,29 & 0,31 \\
& V-bulk & 1,44 & 2,92 & 3,19 \\
\hline \multirow{2}{*}{ Robusta } & v-individual & 0,12 & 0,20 & 0,24 \\
& V-bulk & 1,39 & 2,50 & 3,16 \\
\hline
\end{tabular}

In comparison to individual roasting volume change, the bulk roast volume change was relatively higher. The average bulk roast volume change of Arabica, from GB to RB1, GB to RB2 and RB1 to RB2 was 50.55\%, 54.65\%, and 8.29\%, and that of Robusta was $44.30 \%, 55.92 \%$, and $20.81 \%$. Results of paired t-test analysis determined that the roast volume change from GB to RB1, GB to RB2, and RB1 to RB2 for both Arabica and Robusta coffee bean were significant differences, $\mathrm{t}(3), \mathrm{p}=0.00$.

In the roasting process, the temperature increased, and transformation of water into gas created high levels of pressure inside the bean; this condition changed the structure of the cell walls from rigid to rubbery. The internal matter pushed out toward the cell wall and leaving a gas-filled void in the centre; this meant that the bean expanded in volume, and declined in mass. The packaging for the roasted coffee bean is, therefore, has to be bigger than that of green coffee bean.

\subsection{Density and Porosity}

Table 5 showed particle density, bulk density and bulk porosity of green and roasted Arabica and Robusta coffee bean. Of either particle or bulk density for both Arabica and Robusta coffee bean, there had been a decline. Results of paired t-test analysis determined that the roasting process affected the changing of the particle and bulk density of both Arabica and Robusta coffee bean significantly at the condition of $\mathrm{t}(29), \mathrm{p}<0$, and $\mathrm{t}(4), \mathrm{p}<0$, respectively.

Table 5. The particle density, bulk density and bulk porosity of green and roasted arabica and robusta coffee bean

\begin{tabular}{|c|c|c|c|c|c|c|}
\hline \multirow{2}{*}{ Properties } & \multicolumn{3}{|c|}{ Arabica } & \multicolumn{3}{c|}{ Robusta } \\
\cline { 2 - 7 } & GB & RB1 & RB2 & GB & RB1 & RB2 \\
\hline$\rho \mathrm{p}$ & 1,28 & 0,60 & 0,55 & 1,43 & 0,73 & 0,56 \\
$\rho_{\mathrm{b}}$ & 0,69 & 0,35 & 0,31 & 0,72 & 0,40 & 0,32 \\
$\varepsilon$ & 0,5 & 0,41 & 0,45 & 0,50 & 0,48 & 0,44 \\
\hline
\end{tabular}

The changing in bulk porosity of Arabica coffee bean from GB to RB1 was a significant difference, $t(4), p=0.03$, and their changes from GB to RB2 and RB1 to RB2 were no significant difference at the condition of $t(4), p=0.27$ and $t(4)$, $\mathrm{p}=0.08$. The changing in the porosity of Robusta coffee bean from GB to RB1 and RB1 to RB2 were no significant difference, $t(4), p>0.05$ : otherwise, the change from GB to RB2 was different significantly, $t(4), p=0.01$. The difference in density and bulk porosity could remind to the packing used, that for the same weight, the green and roasted coffee beans need different packaging size. Bulk density and porosity are useful in containerization, transportation and separation systems [28].

In comparison to individual porosity, bulk porosity had the opposite characteristics, in which due to roasting the single bean porosity of roasted bean was higher than that of green bean, while that of bulk porosity of roasted bean was smaller than that of green bean. The expanding of individual porosity was caused by high-level pressure due to the increasing temperature in the roasting process, which changed the structure of the cell walls from rigid to rubbery. As a result, it was not only increasing the volume of individual coffee bean but also expanding the single bean porosity. The change in length, width and thickness caused the decrease in bulk porosity of single roasted coffee bean which conversed the shape from ellipsoidal to spherical so that the air cavity gap in the roasted coffee pile got smaller than that of green coffee bean. 


\subsection{Hardness and fracturability}

Table 6 showed the hardness and fracturability of green bean, first and second-levels of the roasted bean. The pattern of the hardness of both Arabica and Robusta coffee bean caused by roasting were were similar. The hardness showed a decrease from GB to RB1 and from RB1 to RB2. The pattern of fracturability of both Arabica and Robusta coffee bean caused by roasting was a decrease from GB to RB1 and an increase from RB1 to RB2.

Table 6. Hardness and fracturability of green and roasted arabica and robusta coffee bean

\begin{tabular}{|c|c|c|c|c|}
\hline \multirow{2}{*}{ Properties } & \multirow{2}{*}{$\begin{array}{c}\text { Coffee Bean } \\
\text { Species }\end{array}$} & \multicolumn{3}{|c|}{ Types of Coffee Bean } \\
\cline { 3 - 5 } & Arabica & 17,67 & 4,63 & 4,25 \\
\multirow{2}{*}{ H } & Robusta & 17,70 & 4,12 & 2,41 \\
\hline \multirow{2}{*}{ F } & Arabica & 1,65 & 0,33 & 0,37 \\
& Robusta & 1,26 & 0,37 & 0,51 \\
\hline
\end{tabular}

Results of paired t-test analysis showed that the change in hardness of both Arabica and Robusta coffee bean from GB to RB1 and RB2 were a significant difference, $\mathrm{t}(4), \mathrm{p}<0.5$; otherwise there was no significant difference of that from $\mathrm{RB} 1$ to $\mathrm{RB} 2, \mathrm{t}(4), \mathrm{p}>0.05$. Another event that arose mechanically due to roasting was that the coffee bean fracturability reduced from GB to RB1 and RB2: but increased from RB1 to RB2. The changing of fracturability of Arabica coffee bean from GB to RB1 and RB2 were a significant difference, $t(4), p=0.00$, but there was no significant difference from $\mathrm{RB} 1$ to $\mathrm{RB} 2, \mathrm{t}(4), \mathrm{p}=0.30$. The fracturability changes of Robusta coffee bean, from GB to RB1 was a significant difference, but there was no significant difference from GB to RB2 ( $\mathrm{t}(4), \mathrm{p}=0.08)$, and from RB1 to RB2 (t $(4), \mathrm{p}=0.71)$.

In a comparison of mechanical properties between Arabica and robusta coffee bean, there was a significant difference in hardness of second-level roasting bean and fracturability of green bean. The significant difference in hardness could be used as a reference to determine the pile of roasting bean packaging; the roasted bean was more brittle than a green coffee bean.

\subsection{The Angle of repose and friction}

Table 7 showed that the angle of repose of coffee bean types on different material surfaces which commonly used as apart of equipment component, i.e. Stainless steel and Aluminium. The angle of repose was classified as the static and dynamic angle of repose. A static angle of repose is referred to as emptying or funnelling, while the dynamic angle of repose is referred to as filling or piling [30]. Analysis results showed that the static angle of repose for both material surfaces on stainless steel and Aluminium was more significant than that of the dynamic angle of repose; this result showed similarities with that conducted by a previous researcher [31]. In material handling systems and bin design, a dynamic angle of repose was critical physical properties [32].

Regarding the earlier published paper [31] the flow of emptying angle of repose of both arabica and robusta coffee bean included in the category medium, $25^{\circ}<\theta \mathrm{E}<40^{\circ}$, while that in filling angle of repose included in the category excellent, $\theta \mathrm{F}<250$.

Table 7. The emptying and filling angle of repose of green and roasted arabica and robusta coffee bean

\begin{tabular}{|c|c|c|c|c|}
\hline \multirow{2}{*}{$\begin{array}{c}\text { Coffee Bean } \\
\text { Species }\end{array}$} & Angle of & \multicolumn{3}{|c|}{ Types of Coffee Bean } \\
\cline { 3 - 5 } & Repose & GB & RB1 & RB2 \\
\hline \multirow{3}{*}{ Arabica } & $\theta$ Ess & 30,62 & 28,48 & 28,37 \\
& $\theta$ Eal & 35,09 & 31,00 & 30,10 \\
& $\theta$ Fss & 13,65 & 11,07 & 10,35 \\
& $\theta$ Fal & 14,99 & 11,92 & 11,51 \\
\hline \multirow{3}{*}{ Robusta } & $\theta$ Ess & 33,91 & 33,70 & 32,24 \\
& $\theta$ Eal & 32,70 & 31,99 & 29,42 \\
& $\theta$ Fss & 12,61 & 12,22 & 10,74 \\
& $\theta$ Fal & 12,48 & 11,96 & 9,89 \\
\hline
\end{tabular}

Table 7 also showed that the moisture content affected the angle of repose; this result was corresponding with that of the earlier study; the higher the moisture content, the higher the angle of repose [34]. The static angle of repose was an 
essential parameter to design the drop chute of door release which, delivered roasted coffee bean from roaster drum to cooling bin unit.

Table 8. Static friction of green and roasted arabica and robusta coffee bean on a different type of surface materials

\begin{tabular}{|c|c|c|c|c|}
\hline \multirow{2}{*}{$\begin{array}{c}\text { Coffee Bean } \\
\text { Species }\end{array}$} & \multirow{2}{*}{$\begin{array}{c}\text { Static } \\
\text { Friction }\end{array}$} & \multicolumn{3}{|c|}{ Types of Coffee Bean } \\
\cline { 3 - 5 } & & GB & RB1 & RB2 \\
\hline \multirow{2}{*}{ Arabica } & $\mu \mathrm{ss}$ & 0,596 & 0,543 & 0,542 \\
& $\mu \mathrm{al}$ & 0,706 & 0,605 & 0,581 \\
\hline \multirow{2}{*}{ Robusta } & $\mu \mathrm{ss}$ & 0,670 & 0,670 & 0,630 \\
& $\mu \mathrm{al}$ & 0,640 & 0,630 & 0,570 \\
\hline
\end{tabular}

Table 8 showed the static friction of arabica and robusta coffee bean on different material surfaces, i.e. Stainless steel and Aluminium. Results of analysis determined that the static friction was a tangential function of static angle of repose. As was the static angle of repose, the static friction was not also affected by shape and size, but also by moisture content [34].

\subsection{Colours}

Table 9 showed the geometric coordinate (L, a,b, C, H) of arabica and robusta green coffee bean, first and secondlevel of roasting beans. Before roasting, coffee beans are blue-green. They change to brown on account of the production of melanoidins [17].

Results of measurement determined that the roasting process change the geometric coordinates of both arabica and robusta coffee beans. The changing occurred was decreasing the lightness (L), red/green coordinate (b), and chroma (C), and increasing the yellow/blue coordinate (b); while the hue $(\mathrm{H})$ was relatively constant. The total colour difference between GB-RB1, GB-rb2 and RB1-RB2 of arabica coffee bean were 6.39, 2.53, and 1.59, respectively; while that of robusta coffee bean were $6,19,2.49$, and 1.58, respectively. Regarding general degree L, the colour values of first and second level roasting bean of both Arabica and robusta could be categorised as light and medium roast [35, 36].

Table 9. Coordinates of green and roasted arabica and robusta coffee bean

\begin{tabular}{|c|c|c|c|c|}
\hline \multirow{2}{*}{$\begin{array}{c}\text { Coffee Bean } \\
\text { Species }\end{array}$} & \multirow{2}{*}{$\begin{array}{c}\text { Colour } \\
\text { Elements }\end{array}$} & \multicolumn{3}{|c|}{ Types of Coffee Bean } \\
\cline { 3 - 5 } & GB & RB1 & RB2 \\
\hline \multirow{5}{*}{ ARABICA } & $\mathrm{L}$ & 58,98 & 29,22 & 24,86 \\
& $\mathrm{a}$ & 5,91 & 11,27 & 11,09 \\
& $\mathrm{~b}$ & 17,74 & 8,03 & 4,88 \\
& $\mathrm{C}$ & 18,73 & 13,86 & 12,15 \\
& $\mathrm{H}$ & 0,01 & 0,00 & 0,00 \\
\hline \multirow{5}{*}{ ROBUSTA } & $\mathrm{L}$ & 64,90 & 30,27 & 25,06 \\
& $\mathrm{a}$ & 5,68 & 11,07 & 9,90 \\
& $\mathrm{~b}$ & 21,44 & 9,53 & 3,34 \\
& $\mathrm{C}$ & 22,19 & 14,75 & 10,46 \\
& $\mathrm{H}$ & 0,00 & 0,00 & 0,00 \\
\hline
\end{tabular}

According to Lokker [37], a colour value is convenient to categorise the roasting level. Even though the colour is not an especially accurate way of judging a roast, but at least it can illustrate the taste of the roasted bean. Light Roast Coffee pronounce acidity, clear and mild cup, more origin flavours. Medium Roast Coffee has a balance between acidity, sweetness and aromas. Medium-Dark Roast Coffee has a lower acidity, more chocolate-like notes, and heavier mouthfeel; and Dark Roast Coffee notes of dark chocolate and heavy mouthfeel [38].

\section{CONCLUSION}

In general, roasting caused the change of physical, mechanical and colour of the green coffee bean. Results of pair ttest analysis showed that in terms of size and dimension of arabica coffee bean, most of all green bean (GB) properties 
changed significantly different to that of first (RB1) and second - level roasted bean (RB2), except for coefficient of surface contact. There was the disproportionate expansion of length, width and thickness of the bean. Expansion of Arabica coffee bean tended to elongate rather than the width or thickness, and that of Robusta tended to widen rather than elongated and thickened.

In the matter of a mass and volume, results of analysis determined that there were significantly changed from the green bean to both first level and the second level roasted bean $(\mathrm{p}<0.05)$. In comparison between first and second level roasted bean, results of analysis determined that all of the shape and properties of the first level roasted bean was not significantly different ( $p>0.05)$, except for the length of the coffee bean $(\mathrm{p}<0.05)$.

On the subject of particle and bulk densities, the green coffee bean to two-levels of roasted bean changed significantly $(\mathrm{p}<0.05)$, and similar changes occurred from the first to second level roasted bean $(\mathrm{p}<0.05)$. In respect of bulk porosity, there was a significant change from green bean to the first level of the roasted bean. Otherwise, there was not any substantial change from green bean to second level roasted bean, and from first to the second level of the roasted bean.

Concerning the hardness, the change of both Arabica and Robusta coffee bean from GB to RB1 and RB2 were a significant difference, $\mathrm{p}<0.5$; otherwise there was no significant difference of that from $R B 1$ to $R B 2, p>0.05$. The coffee bean fracturability reduced from GB to RB1 and RB2: but increased from RB1 to RB2. The changing of fracturability of Arabica coffee bean from GB to RB1 and RB2 were significant difference, $p=0.00$, but there was no significantly different from RB1 to RB2, $\mathrm{p}=0.30$; while that of Robusta coffee bean, there was significant difference from GB to RB1, but there was no significant difference from $G B$ to $R B 2, p=0.08$, and from RB1 to $R B 2 p=0.71$. In a comparison of mechanical properties between Arabica and Robusta coffee bean, there was a significant difference in hardness of second-level roasting bean and fracturability of green bean.

Concerning the angle of repose, the static was higher than that of dynamic. The flow of emptying angle of repose of both arabica and robusta coffee bean was categorised as a medium, $250<\theta \mathrm{E}<400$, while that in filling angle of repose included in the category excellent, $\theta \mathrm{F}<250$. The static friction was the tangential function of emptying angle of repose.

Regarding the general degree of lightness, the colour values of first and second level roasting bean of both Arabica and Robusta could be categorised as a light and medium roast. The total colour difference between green bean - lightly roasted bean, green bean - medium roasted bean and lightly -medium roasted bean of arabica coffee bean were 6.39, 2.53 , and 1.59, respectively; while that of robusta coffee bean were $6,19,2.49$, and 1.58 .

\section{ACKNOWLEDGEMENT}

This study was a part of coffee-based agro-industry development, Program of National Priority, and Science and Technology for the Region, conducted by Research Center For Appropriate Technology - Indonesian Institute of Sciences. We would like to appreciate all those who offered us the possibility to complete this report. We also would like to thank the metal mechanic workshop and food laboratory technicians for their help in carrying out this study.

\section{REFERENCES}

[1] The World Bank, Agro-Industry Proffles: Coffee, Report FAU-14 (The World Bank), Washingto DC, 1985.

[2] Mohammed sani A A, "Physical Quality Analysis of Roasted Arabica Coffee Beans Subjected to Different Harvesting and Postharvest Processing Methods in Eastern Ethiopia" Journal of Food Science and Quality Management, Vol.57, 2016.

[3] Kah Yau Ee, Jian Zhao, Ata-Ur Rehman Samson Agboola, "Effects of roasting on the characteristics of Australian wattle (Acacia Victoriae Bentham) seed and extracts" International Journal of Food Properties vol. 16, No. 5, pp.1135-1147, 2013.

[4] Ola Lasekan, Alfi Khatib, Kassim A Abbas, "Volatile compounds of roasted and steamed Malaysian tropical almond nut (Terminalia catappa L.)", International Journal of Food Properties, Vol. 15, No. 5, pp.1120-1132, 2012.

[5] Joanna Oracz, Ewa Nebesny, "Antioxidant properties of cocoa beans (Theobroma cacao 1.): influence of cultivar and roasting conditions" International Journal of Food Properties, Vol. 19, No. 6, pp.1242-1258, 2016.

[6] Sievetz, Desrosier, Coffee Technology. Westport: AVI Publishing Company.In Niya Wang. 2012. Physicochemical Changes of Coffee Beans During Roasting, (The University of Guelph) Canada, 1979.

[7] Anna G Fiore, Carla Severini, Roberto Romaniello, Giorgio Peri, "Study of Physical Properties of Coffee Beans during Roasting. Application of Hyperspectral Image Analysis", In 21st International Conference on Coffee ScienceAt: Montpellier (France), 2016.

[8] Niya Wang, Physicochemical Changes of Coffee Beans During Roasting (The University of Guelph), Canada, 2012.

[9] J Vosloo, Heat and mass transfer model for a coffee roasting process (the North-West University), Afrika, 2017.

[10] Cameron Kelly, The Art of Coffee Roasting, Investigations into Sensor Development for the Application of Controlling Coffee Roasting, (The University of Waikato) New Zealand, 2018. 
[11] Jokanović R Marija, Džinić R Natalija, Biljana Cvetkovic, Grujic Slavica, Odžaković Božana, "Changes of physical properties of coffee beans during roasting”, Acta Periodica Technologica, Vol. 43, pp. 21-31, 2012.

[12] A Illy, R Viani, Espresso Coffee, Second Edition: The Science of Quality (Academic Press), Amerika, 2005.

[13] J A Hernándeza, B.Heyd, C Irles, Valdovinos, G Trystram, "Analysis of the heat and mass transfer during coffee batch roasting", Journal of Food Engineering, Vol. 78,No. 4, pp.1141-1148, 2007.

[14] A M Fareez Edzuan, A M Noor Aliah, H L Bong, "Physical and Chemical Property Changes of Coffee Beans during Roasting", American Journal of Chemistry, Vol. 5, No. 3, pp.56-60, 2015.

[15] E R Dutra, L S Oliveira, A S Franca, V P Ferrez, R J Afonso, "A preliminary study on the feasibility of using the composition of coffee roasting exhaust gas for the determination of the degree of roast", Journal of Food Engineering, Vol. 47, pp.241-246, 2001.

[16] P Pittia, M C Nicoli, G Sacchetti, "Effect of moisture and water activity on textural properties of row And roasted coffee beans", Journal of Texture Studies, Vol. 38, pp.116-134, 2007.

[17] Verônica Belchior, What Happens During Coffee Roasting: The Physical Changes, In Online available on https://www.perfectdailygrind.com/2019/03/what-happens-during-coffee-roasting-the- physical-changes/ Accessed on $9 / 16 / 2019,2019$.

[18] W, Burubai, A J Akor, A H Igoni, Y T Puyate, "Effects of temperature and moisture content on the strength properties of African nutmeg (Monodora myristica)", International Agrophysics, Vol. 21, pp.217-223, 2007.

[19] N N Mohsenin, Physical properties of plant and animal materials, (Gordon and Breach Publishers) New York, 1986.

[20] A A Mohammedsani, "Physical Quality Analysis of Roasted Arabica Coffee Beans Subjected to Different Harvesting and Postharvest Processing Methods in Eastern Ethiopia", Food Science and Quality Management, Vol.57, 2016.

[21] V Chandrasekar, R Viswanathan, "Physical and thermal properties of coffee", Journal of Agricultural Engineering Research, Vol. 73, pp.227-234, 1999.

[22] Bart-Plange A, Edward A. Baryeh, "The physical properties of Category B cocoa beans", Journal of Food Engineering, Vol. 60, pp.219-227, 2003.

[23] K K Singh, T K Goswami, "Physical properties of cumin seed", Journal of Agricultural Engineering Research, Vol. 64, pp.93-98, 1996.

[24] S H Suthar, S K Das, "Some physical properties of karinga seeds", Journal of Agricultural Engineering Research, Vol. 65, pp.15-22, 1996.

[25] F J Ruiz, Nuria Agell, Cecilio Angulo, Monica Sanchez, “A qualitative learning system for human sensory abilities in adjustment tasks" In 26th International workshop on qualitative reasoningAt: Playa Vista, California, Estados Unidos de América, 2012.

[26] A S Franca, J C F Mendonca, S D Oliveira, "Composition of green and roasted coffees of different cup qualities", LWT - Food Science and Technology, Vol. 38, No. 7, pp.709-715, 2005.

[27] A Putranto, X D Chen, "Roasting of Barley and Coffee Modeled Using the Lumped-Reaction Engineering Approach (L-REA)" Drying Technology, Vol. 30, No. 5, pp.475-483, 2012.

[28] R P Kachru, R K Gupta, A Alam, Physicochemical constituents and engineering properties Of food crops (Scientific Publishers), Jodhpur, 1994.

[29] R L Stroshine, Physical properties of agricultural materials and food products (West Lafayette, Ind), New York, 2004.

[30] B M Stahl, Grain bin measurements, (USDA Circular), Washington DC, 1950.

[31] R T Fowler, F A Wyatt, "The effect of moisture content on the angle of repose of granular solids", Australian J. Chem.Eng, Vol.1, pp.5-8, 1960.

[32] G A Anderson, C J Bern, Dynamic Angle of Repose of Corncobs Placed by Three Mechanical Means, (IOWA State University), Inggris, 1984.

[33] Edward Lau (Deceased), Preformulation Studies in Separation Science and Technology-Handbook of Modern Pharmaceutical Analysis Copyright, (Academic Press A Harcourt Science and Technology Company), USA, 2001.

[34] J Khazaei, S Ghanbari, "New method for simultaneously measuring the angles of repose and frictional properties of wheat grains", International Agrophysi, Vol. 24, pp.275-286, 2010.

[35] J Baggenstoss, L Poisson, R Luethi, R Perren, F Escher, "Influence of Water Quench Cooling on Degassing and Aroma Stability of Roasted Coffee", J. Agric. Food Chem, vol. 55, no. 16, pp. 6685-6691, 2007.

[36] H G Schwartzberg, Batch Coffee Roasting; Roasting Energy Use; Reducing That Use. (In Yanniotis, S., Taoukis, P., Stoforos, N.G. \& Karathanos, V.T., eds. Advances in Frood Process Engineering Research and Applications. 1st ed (Springer), New York, 2013.

[37] B Lokker, Coffee Roasts from Light to Dark, Coffee Crossroads, In Online available at: https://www.coffeecrossroads.com/coffee-101/coffee-roasts-from-light-to-dark . Accessed on 09/16/2019, 2013

[38] Mattia, How Coffee Roasting Levels Affect Flavors, In Online available at:Jhttps://www.ticocoffee.com/en/blog/coffee-roasting/coffee-roasting-levels.html. Accessed on 9/16/2019. 2017 